\title{
Molecular basis of ocular abnormalities associated with proximal renal tubular acidosis
}

\author{
Tomohiko Usui, ${ }^{1}$ Masumi Hara, ${ }^{2}$ Hiroaki Satoh, ${ }^{2}$ Nobuo Moriyama, ${ }^{3}$ Humie Kagaya, ${ }^{1}$ \\ Shiro Amano, ${ }^{1}$ Tetsuro Oshika, ${ }^{1}$ Yasuo Ishii, ${ }^{4}$ Nobuhiro Ibaraki, ${ }^{5}$ Chiaki Hara, ${ }^{2}$ \\ Motoei Kunimi, ${ }^{2}$ Eisei Noiri, ${ }^{2}$ Kazuhisa Tsukamoto, ${ }^{2}$ Jun Inatomi, ${ }^{6}$ Hayato Kawakami, ${ }^{7}$ \\ Hitoshi Endou, ${ }^{6}$ Takashi Igarashi, ${ }^{8}$ Astuo Goto, ${ }^{2}$ Toshiro Fujita, ${ }^{2}$ Makoto Araie, ${ }^{1}$ \\ and George Seki ${ }^{2}$
}

${ }^{1}$ Department of Ophthalmology,

${ }^{2}$ Department of Internal Medicine, and

${ }^{3}$ Department of Hemodialysis and Apheresis, Faculty of Medicine, Tokyo University, Bunkyo-ku, Tokyo, Japan

${ }^{4}$ New Vision Eye Institute, Taito-ku, Tokyo, Japan

${ }^{5}$ Department of Ophthalmology, Nihon Medical University, Bunkyo-ku, Tokyo, Japan

${ }^{6}$ Department of Pharmacology and Toxicology, and

${ }^{7}$ Department of Anatomy, Kyorin University School of Medicine, Mitaka, Tokyo, Japan

${ }^{8}$ Department of Pediatrics, Faculty of Medicine, Tokyo University, Bunkyo-ku, Tokyo, Japan

Address correspondence to: George Seki, Department of Internal Medicine, Faculty of Medicine,

Tokyo University, 7-3-1 Hongo, Bunkyo-ku, Tokyo 113-0033, Japan.

Phone: 81-3-3815-5411 ext. 33004; Fax: 81-3-5800-8806; E-mail: georgeseki-tky@umin.ac.jp.

Received for publication January 29, 2001, and accepted in revised form May 14, 2001.

\begin{abstract}
Proximal renal tubular acidosis associated with ocular abnormalities such as band keratopathy, glaucoma, and cataracts is caused by mutations in the $\mathrm{Na}^{+}-\mathrm{HCO}_{3}{ }^{-}$cotransporter $(\mathrm{NBC}-1)$. However, the mechanism by which NBC-1 inactivation leads to such ocular abnormalities remains to be elucidated. By immunological analysis of human and rat eyes, we demonstrate that both kidney type (kNBC-1) and pancreatic type (pNBC-1) transporters are present in the corneal endothelium, trabecular meshwork, ciliary epithelium, and lens epithelium. In the human lens epithelial (HLE) cells, RT-PCR detected mRNAs of both $\mathrm{kNBC}-1$ and $\mathrm{pNBC}-1$. Although a $\mathrm{Na}^{+}-\mathrm{HCO}_{3}^{-}$cotransport activity has not been detected in mammalian lens epithelia, cell $\mathrm{pH}\left(\mathrm{pH}_{\mathrm{i}}\right)$ measurements revealed the presence of $\mathrm{Cl}^{-}$-independent, electrogenic $\mathrm{Na}^{+}-\mathrm{HCO}_{3}{ }^{-}$cotransport activity in $\mathrm{HLE}$ cells. In addition, up to $80 \%$ of amiloride-insensitive $\mathrm{pH}_{\mathrm{i}}$ recovery from acid load in the presence of $\mathrm{HCO}_{3}{ }^{-} / \mathrm{CO}_{2}$ was inhibited by adenovirus-mediated transfer of a specific hammerhead ribozyme against NBC-1, consistent with a major role of NBC-1 in overall $\mathrm{HCO}_{3}{ }^{-}$transport by the lens epithelium. These results indicate that the normal transport activity of NBC-1 is indispensable not only for the maintenance of corneal and lenticular transparency but also for the regulation of aqueous humor outflow.
\end{abstract}

J. Clin. Invest. 108:107-115 (2001). DOI:10.1172/JCI200111869.

\section{Introduction}

The persistent form of isolated proximal renal tubular acidosis (pRTA) is rare, but frequently associated with ocular abnormalities such as band keratopathy, glaucoma, and cataracts (1-4). We have shown recently that inactivating mutations in the $\mathrm{Na}^{+}-\mathrm{HCO}_{3}{ }^{-}$cotransporter (NBC-1) cause this disorder (4). NBC-1, originally cloned from amphibian kidney (5), has at least three isoforms: kNBC-1 from the kidney, pNBC-1 from the pancreas, and hNBC- 1 from the heart. While the patterns of tissue distribution are quite different among these isoforms, pNBC- 1 differs from $\mathrm{kNBC}-1$ only at the $\mathrm{N}$ terminus. In addition, hNBC- 1 is identical to pNBC- 1 at the amino acid level and differs only in its $5^{\prime}$-untranslated region (6-9). These NBC-1 isoforms originate from the common $S L C 4 A 4$ gene by alternative splicing (9). It is therefore possible that mutations in the common NBC-1 region may affect the properties of all these isoforms, resulting in renal and extrarenal manifestations. For example, because $\mathrm{kNBC}-1$ is thought to be responsible for a majority of $\mathrm{HCO}_{3}{ }^{-}$reabsorption from renal proximal tubules (10-12), its inactivation can readily explain the occurrence of PRTA. Recent studies $(13,14)$ suggest that NBC-1 may also play a significant role in $\mathrm{HCO}_{3}^{-}$transport by the corneal endothelium, which potentially could explain the occurrence of band keratopathy (4). However, the mechanism by which NBC-1 inactivation leads to glaucoma and cataracts is completely unknown. Moreover, the exact localization of NBC-1 in the whole eye has not been determined. Elucidation of the roles of NBC- 1 in the eye would be extremely important, since the underlying molecular mechanisms of glaucoma and cataracts, the leading causes of blindness in the world $(15,16)$, are not fully understood. In the present study we performed immunological analysis on human and rat eyes using 
an affinity-purified $\mathrm{Ab}$ that recognizes both kNBC-1 and pNBC-1 (17). To discriminate between these two isoforms of NBC-1, we also raised $A b$ 's against their $\mathrm{N}$ terminal-specific regions. Our results showed that NBC- 1 is present in the corneal endothelium, trabecular meshwork, ciliary epithelium, and lens epithelium. In addition, we revealed that NBC-1 plays a major role in $\mathrm{HCO}_{3}{ }^{-}$transport by the human lens epithelial (HLE) cells. From these observations we propose that the inactivation of NBC-1 directly disrupts the homeostasis of cornea, trabecular meshwork, and lens, resulting in band keratopathy, glaucoma, and cataracts.

\section{Methods}

Immunobistochemistry. In addition to the $\mathrm{Ab}$ against the C-terminal region of NBC-1 (17), two antipeptide $\mathrm{Ab}$ 's were raised against the isoformspecific regions of NBC-1. Synthetic peptides corresponding to the $\mathrm{N}$-terminal regions of human kNBC-1 (amino acids 4-16) or human pNBC-1 (amino acids 2-12) were coupled to C-terminal cysteine, conjugated to keyhole limpet hemocyanin, and affinity-purified Ab's were raised in rabbits as described (17).

Human eyes were obtained from Rocky Mountain Lions Eye Bank (Aurora, Colorado, USA), and rat eyes were enucleated. Specimens were prefixed with $4 \%$ paraformaldehyde in $100 \mathrm{mmol} / \mathrm{l} \mathrm{PBS}$, then embedded into Tissue-Tek OCT (Miles Inc., Elkhart, Illinois, USA), quickly frozen in liquid nitrogen, and stored at $-80^{\circ} \mathrm{C}$ until experiments were performed. For immunoperoxidase detection, frozen eyes were cut into 5- $\mu \mathrm{m}$ thickness. After treatment with goat serum, the sections were incubated with the diluted (1:100) anti-NBC-1 Ab's (common type, anti-kNBC-1, and anti-pNBC-1). The absorption tests were performed in the presence of the corresponding antigen peptides (10 $\mathrm{mg} / \mathrm{l})$. Immunoreactivities were detected by a Histofine SAB-PO Kit (Nichirei Corp., Tokyo, Japan). In brief, the sections were incubated with biotinylated anti-rabbit goat serum, then incubated with streptavidin-biotin-peroxidase. The final reaction product was visualized with $3,3^{\prime}$-diaminobenzidine tetrahydrochloride. For immunofluorescence detection, the prefixed tissues were permeated by sequential incubation in PBS containing $10 \%, 20 \%$, and $30 \%$ sucrose, embedded into Tissue-Tek OCT, and snap-frozen in liquid nitrogen. Sections $10-\mu \mathrm{m}$ thick were prepared, air dried, and immersed in PBS, and treated with 5\% normal donkey serum (Jackson ImmunoResearch Laboratories Inc., West Grove, Pennsylvania, USA), followed by incubation in the diluted (1:100) anti-NBC$1 \mathrm{Ab}$ 's. The sections were then incubated with 3.75 $\mathrm{mg} / \mathrm{l} \mathrm{Cy3-conjugated} \mathrm{Affipure} \mathrm{donkey} \mathrm{anti-rabbit} \mathrm{IgG}$ ( $\mathrm{H}+\mathrm{L}$; Jackson ImmunoResearch Laboratories Inc.) with SYBR green I nucleic acid gel stain (1:50,000 dilution of the stock reagent; Molecular Probes Inc., Eugene, Oregon, USA), and observed with a confocal laser-scanning microscope (MRC-1024K; Japan BioRad Laboratories, Tokyo, Japan).

Cell culture. Immortalized HLE cells (18) were cultured in DMEM (Life Technologies Inc., Grand Island, New York, USA) containing 20\% FBS and 20 $\mathrm{mg} / \mathrm{l}$ gentamycin. They were trypsinized by $0.05 \%$ trypsin/EDTA solution and subcultured onto $6-\mathrm{mm}$ round glass coverslips to be used for the intracellular $\mathrm{pH}\left(\mathrm{pH}_{\mathrm{i}}\right)$ measurements.

RT-PCR. RT-PCR was performed using the cDNA template derived from mRNA of HLE cells as described previously (17). The conditions for PCR were as follows: 30 cycles of 30 seconds at $94^{\circ} \mathrm{C}, 30$ seconds at $60^{\circ} \mathrm{C}$, and 45 seconds at $72^{\circ} \mathrm{C}$, with an initial 9-minute denaturing step and a final 7-minute elongation step. Based on the sequences of human kNBC-1 and pNBC-1 $(6,7)$, four sets of primers were designed in the isoform-specific regions as well as the common region. The primer set for the kNBC-1-specific region was $5^{\prime}$-GCCCAGTAACCTTGGGGAGA-3' (sense) and 5'-GCAGAAGTGAAAATACTGTGG-3' (antisense), corresponding to nucleotides $175-84$ and $248-268$ in human kNBC1 mRNA. The primer set for the pNBC-1-specific region was $5^{\prime}$-ATGGAGGATGAAGCTGTCCTG-3' (sense) and $5^{\prime}$-CCGATGTAAATGGTATGGTGG-3' (antisense), corresponding to nucleotides $118-138$ and $192-212$ in human pNBC-1 mRNA. One of the primer sets for the common region was $5^{\prime}$-CCTCAGCTCTTCACGGAACT- $3^{\prime}$ (sense) and 5'-AGCATGACAGCCTGCTGTAG-3' (antisense), corresponding to nucleotides 333-352 and 930-949 in kNBC-1 (or 433-452 and 1030-1049 in pNBC-1). Another set for the common region near the C terminus was $5^{\prime}$-TGGCTCCCATCTTGAAGTTTA-3' (sense) and 5'-CAGCTACAAGTGCCAAGATCA-3' (antisense), corresponding to nucleotides 2695-2716 and 2973-2994 in kNBC-1 (or 2795-2816 and 3073-3094 in pNBC-1). The amplified fragments by RT-PCR were subcloned into a TA vector (Invitrogen Corp., San Diego, California, USA), and sequenced. 
Measurement of $p H_{i}$. Cell-coated coverslips were incubated with $\mathrm{HCO}_{3}-$-free, HEPES-buffered Ringer's solution containing $10 \mu \mathrm{mol} / \mathrm{l}$ bis(carboxyethyl)carboxyfluorescein/ acetoxymethylester (BCECF/AM) for 30-60 minutes at room temperature. The coverslip was then superfused with prewarmed $\left(38^{\circ} \mathrm{C}\right)$ experimental solutions (Table 1 ) at approximately $5 \mathrm{ml} / \mathrm{min}$ in a chamber mounted on an inverted microscope (IMT-2; Olympus Optical Co., Tokyo, Japan), and $\mathrm{pH}_{\mathrm{i}}$ was measured with a microscopic fluorescence photometry system (OSP-10; Olympus Optical Co.) as described previously $(13,17)$. The intracellular dye was alternately excited at two wavelengths (440 and 490 $\mathrm{nm}$ ), and emission was measured at a wavelength of $530 \mathrm{~nm}$. Autofluorescence of cells was measured at the beginning of an experimental day, and these values were subtracted from the raw data. We used nigericin to acidify the cells as reported previously $(4,17)$, since the pilot experiments revealed that this method induced a more stable and predictable acidification than the $\mathrm{NH}_{4} \mathrm{Cl}$-pulse technique in this cell line. However, in some experiments we also used $\mathrm{NH}_{4} \mathrm{Cl}$ to acidify the cells, and in this case $20 \mathrm{mmol} / \mathrm{l} \mathrm{NaCl}$ in solution a was replaced with the equimolar amount of $\mathrm{NH}_{4} \mathrm{Cl}$. The calibration curve for $\mathrm{pH}_{\mathrm{i}}$ was made according to the method of Thomas et al. (19). In brief, cells were exposed to HEPES-buffered solution containing $120 \mathrm{mmol} / \mathrm{l} \mathrm{K}$ and $10 \mu \mathrm{mol} / \mathrm{l}$ nigericin, and solution $\mathrm{pH}$ was adjusted at the different levels (from 6.4 to 7.8 ) with $1 \mathrm{~N} \mathrm{NaOH}$. The results were expressed as mean values plus or minus SEM. Statistical analysis was determined using the unpaired $t$ test or the MannWhitney test for single comparisons of groups. ANOVA with Bonferroni's adjustment was used for multiple comparisons of data. A $P$ value of less than 0.05 was considered statistically significant. BCECF/AM was obtained from Dojindo Laboratories (Kyushu, Japan), and 4, 4'-diisothiocyanatostilbene-2, $2^{\prime}$-disulphonic acid (DIDS), amiloride, valinomycin, and nigericin were from Sigma Chemical Co. (St. Louis, Missouri, USA). All the other chemicals were from Wako Pure Chemicals Industries (Osaka, Japan), unless otherwise specified.

Construction of a hammerhead ribozyme against NBC-1. After the coding region of human valine tRNA was subcloned into a TA cloning vector PCR2.1 (Invitrogen Corp.), 9-bp deletion was introduced in the anticodon region to gain the unique restriction enzyme site of NruI. The oligonucleotide, $5^{\prime}$-AACATCCCTGATGAGTCCGTGAGGACGAAACTTGC- $3^{\prime}$, and the complementary oligonucleotide were annealed together and subcloned into the NruI site of this plasmid to construct a NBC1 mRNA-specific hammerhead ribozyme, RZ-NBC. The RZ sequence consisted of two flanking regions complementary to NBC-1 mRNA, targeting at the NBC- 1 common region $\left(\mathrm{GUA}^{723}\right.$ in $\mathrm{kNBC}-1$ or $\mathrm{GUA}^{823}$ in pNBC-1), and a conserved catalytic sequence (20). The plasmid was then subcloned into pAdCMVlink lacking cytomegalovirus enhancer and promoter, lin- earized with EcoRI, and cotransfected to 293 cells together with adenoviral DNA digested with ClaI to construct the adenovirus vector carrying RZ-NBC. The adenovirus vector carrying the ribozyme against the microsomal triglycerides transfer protein (21) (RZMTP) was constructed as described above, except the oligonucleotides were designed to target the MTP gene (at GUC ${ }^{674}$ ). To examine the effects of RZ transfer into HLE cells, the cells were infected with $5 \times 10^{6} \mathrm{pfu} / \mathrm{ml}$ (8 moi) of adenovirus vector containing RZ-NBC, RZ-MTP, or LacZ gene for 2 hours in DMEM without FBS. After the cells were incubated in DMEM containing 20\% FBS for 48 hours, $\mathrm{pH}_{\mathrm{i}}$ measurement and Western blot analysis were performed.

Western blot analysis. Western blot analysis was performed as described previously (17). In brief, HLE cells were lysed, and the membrane fraction was obtained by differential and discontinuous sucrose-gradient procedures as described (17). Protein concentrations were measured spectrophotometrically using a Bio-Rad Laboratories Inc. (Richmond, California, USA) protein assay kit. Equal amounts of protein $(50 \mu \mathrm{g} / \mathrm{lane})$ were dissolved in sample buffer, boiled for 5 minutes, separated by SDS-PAGE on 7\% acrylamide minigels, and blotted onto a nitrocellulose membrane. After incubation in blocking buffer, the membrane was treated with the diluted (1:200) Ab against the NBC-1 C-terminal region and then with horseradish peroxidase-conjugated anti-rabbit IgG (Bio-Rad Laboratories Inc.) as the secondary $\mathrm{Ab}$. The signal was detected by an ECL Plus system (Amersham International, Amersham, United Kingdom). To test for the specificity of anti-NBC-1 Ab's, we transiently transfected ECV304 cells with either human kNBC- 1 cDNA or human pNBC-1 cDNA, using nontransfected cells as a negative control as described previously (17). Two days after transfection, the membrane fraction was obtained, and Western blot analysis was performed as described above using the three different anti-NBC-1 Ab's as the primary $\mathrm{Ab}$.

\section{Results}

Specificity of anti-NBC-1 Ab's. To test for the specificity of anti-NBC-1 Ab's, we transiently expressed either

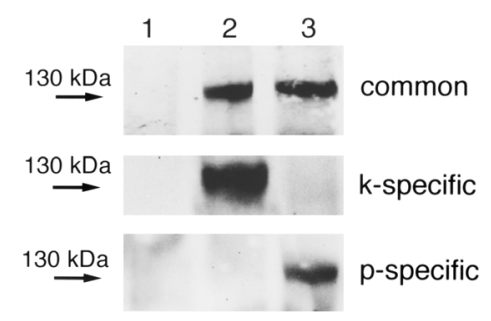

\section{Figure 1}

Characterization of anti-NBC-1 Ab's. Lane 1: nontransfected ECV304 cells. Lane 2: cells transfected with kNBC-1 cDNA. Lane 3: cells transfected with pNBC-1 cDNA. Western blot analysis was performed using the Ab's against the NBC- $1 \mathrm{C}$ terminus (common), the kNBC- $1 \mathrm{~N}$ terminus ( $k$-specific), and the $\mathrm{pNBC}-1 \mathrm{~N}$ terminus ( $\mathrm{p}$-specific). A representative blot from three independent experiments is shown. 
a

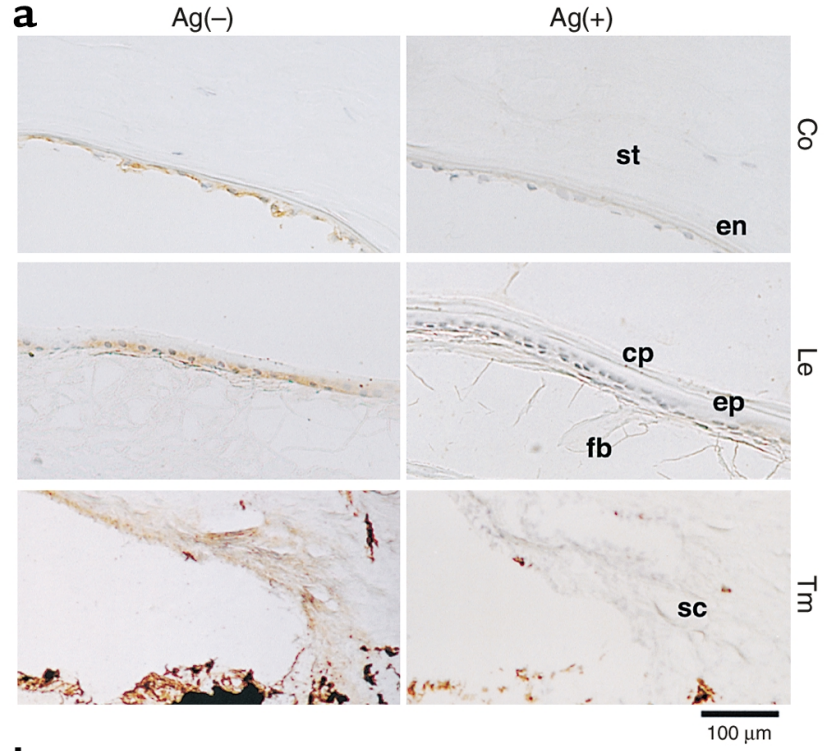

b

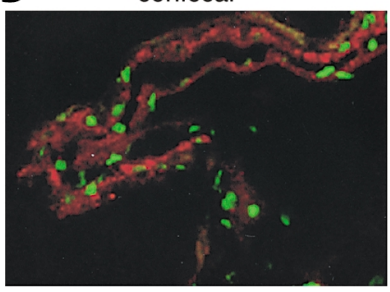

C
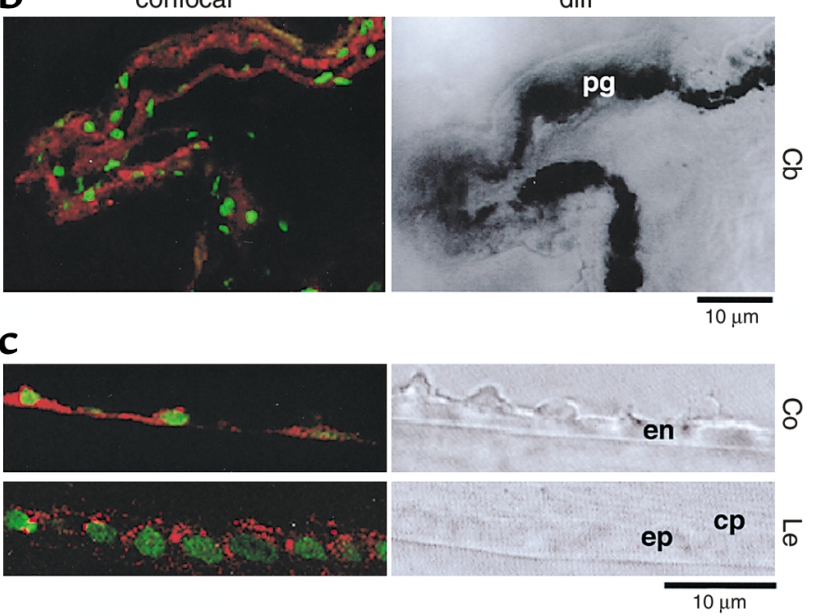

Figure 2

Immunolocalization of NBC-1 in the eyes. (a) Peroxidase-antiperoxidase staining of the human eye in the absence, $\mathrm{Ag}(-)$, and presence, $\mathrm{Ag}(+)$, of the antigen peptide. NBC-1 staining is brown. Co, cornea; Le, lens; Tm, trabecular meshwork; st, corneal stroma; en, corneal endothelium; cp, lens capsule; ep, lens epithelium; fb, lens fiber cells; sc, Schlemm's canal. (b and c) Confocal laser microscopic image (confocal) and Nomarski-differential interference microscopic image (diff) of human (b) and rat (c) eyes. Red shows the localization of NBC-1 and green shows nuclei. Cb, ciliary body; pg, pigmented ciliary epithelium.

kNBC-1 or pNBC-1 in ECV304 cells and performed Western blot analysis. As shown in Figure 1, the $\mathrm{Ab}$ against the NBC-1 C-terminal region recognized both $\mathrm{kNBC}-1$ and $\mathrm{pNBC}-1$ proteins expressed in these cells as reported previously (17). Figure 1 also shows that the $\mathrm{Ab}$ against the $\mathrm{kNBC}-1 \mathrm{~N}$-terminal region recognized only the $\mathrm{kNBC}-1$ protein, whereas the $\mathrm{Ab}$ against the pNBC-1 N-terminal region recognized only the pNBC1 protein, confirming the specificity of these $A b$ 's.

Localization of NBC-1 in the eye. To determine the localization of NBC-1 in the eye, we first used the $\mathrm{Ab}$ against the $\mathrm{C}$-terminal region of NBC-1 (common $\mathrm{Ab}$ ).
Using the immunoperoxidase detection method, we identified an intense staining in the corneal endothelium, lens epithelium, and trabecular meshwork in the human eye (Figure 2a). The nonimmunized rabbit IgG gave no staining. Furthermore, the labeling by the anti-NBC-1 Ab was diminished in the presence of the antigen peptide, confirming the specificity of immunoreactions. With the immunofluorescencedetection method using confocal microscopy, a clear localization was evident in both nonpigmented and pigmented ciliary epithelia of the human eye (Figure $2 \mathrm{~b})$. In the rat eye, the labeling in the corneal endothelium appeared rather basolateral dominant, while the lens epithelium was more diffusely labeled (Figure 2c). Virtually identical results were obtained in the human eye. The other ocular tissues such as sclera, conjunctiva, corneal epithelium and stroma, lens fiber cells, ciliary muscle cells, and retina were not labeled.

To determine which NBC-1 isoform is expressed in these ocular tissues, we next performed immunohistological analysis using the isoform's specific Ab's. In essence, we found that kNBC- 1 and pNBC- 1 are similarly distributed in the eye. In the human eye we detected the expression of both kNBC-1 and pNBC-1 in the corneal endothelium and trabecular meshwork using the immunoperoxidase-detection method (Figure 3a). The labeling by these Ab's was diminished in the presence of corresponding antigen peptides. In the rat eye we also detected the expression of both NBC-1 isoforms in the ciliary epithelium, corneal endothelium, and lens epithelium using the immunofluorescence-detection method (Figure $3 b$ ). In the rat corneal endothelium and lens epithelium, the expression of kNBC-1 appeared rather dominant in the basolateral membranes (the stroma side in cornea and the capsule side in lens), whereas PNBC-1 seemed to be expressed more diffusely.

NBC-1 in HLE cells. These immunohistological findings suggest that $\mathrm{NBC}-1$ represents a $\mathrm{Na}^{+}-\mathrm{HCO}_{3}$ cotransport activity reported previously in the corneal endothelium $(13,14,22)$, ciliary epithelium $(23,24)$, and trabecular meshwork (25). However, the cotransport activity has not been detected in the mammalian lens epithelium (26). We therefore examined whether NBC-1 is expressed in HLE cells, the immortalized cells derived from the human lens epithelium (18). As shown in Figure 4, RT-PCR on the common NBC-1 region yielded amplified bands of the expected size (lane 1, $617 \mathrm{bp}$; lane 4, $300 \mathrm{bp}$ ). In addition, RT-PCR on the pNBC-1-specific region (lane 2, $95 \mathrm{bp}$ ) as well as the kNBC-1-specific region (lane 3; $94 \mathrm{bp}$ ) also yielded the expected bands. The sequences determined from each amplified cDNA fragments were completely identical to those of the corresponding portions of human $\mathrm{kNBC}-1$ and $\mathrm{pNBC}-1$.

To examine whether these cells have the transport activity compatible with $\mathrm{NBC}-1, \mathrm{pH}_{\mathrm{i}}$ measurements were next performed. Figure 5a shows an acid-load experiment in the absence of $\mathrm{HCO}_{3}{ }^{-} / \mathrm{CO}_{2}$. After acidi- 
a

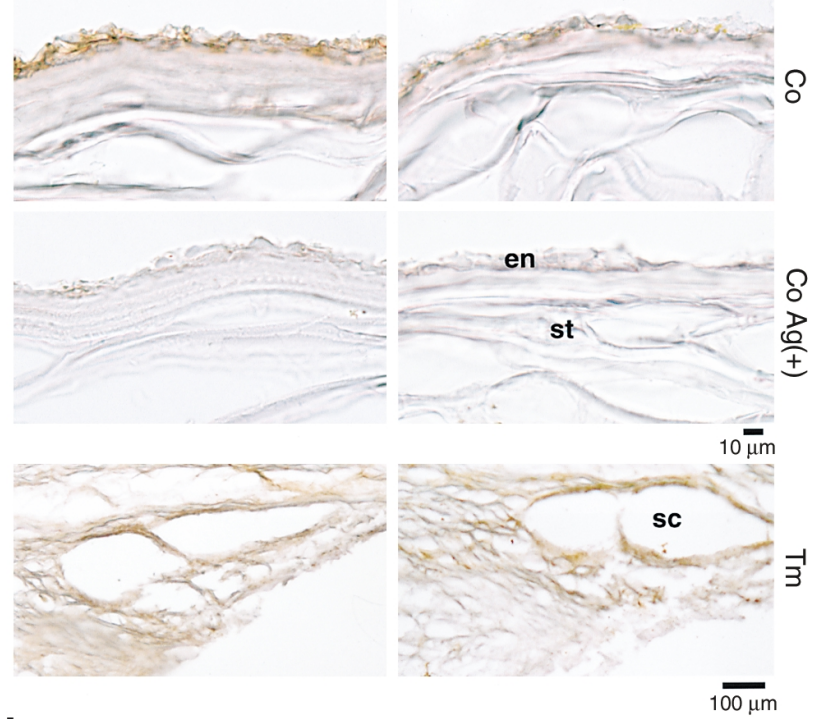

b
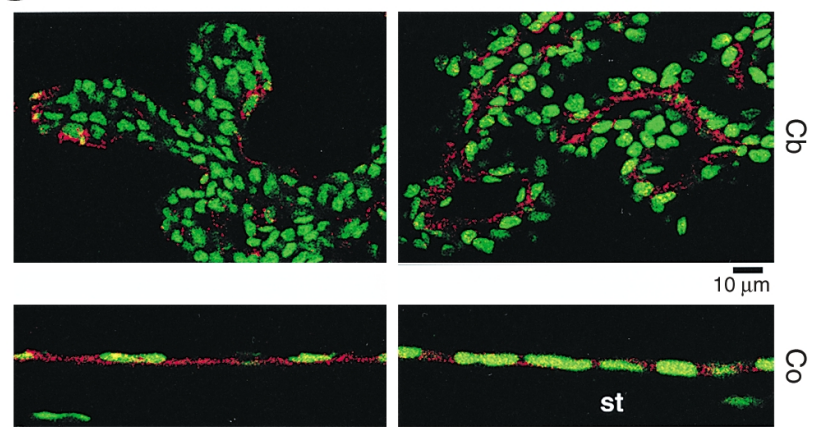

$10 \overline{\mu m}$
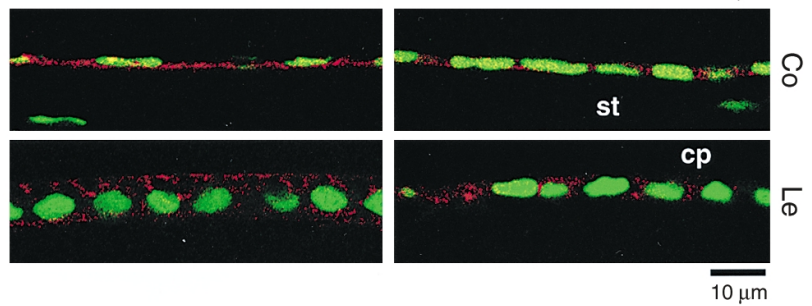

Figure 3

The expression of NBC-1 isoforms in the eyes. (a) Peroxidase-antiperoxidase staining of the human cornea and trabecular meshwork. (b) Confocal laser microscopic image of the rat ciliary body, cornea, and lens. Details as in Figure 2.

fication by nigericin, cells did not show any $\mathrm{pH}_{\mathrm{i}}$ recovery in the absence of extracellular $\mathrm{Na}^{+}$. However, readdition of $\mathrm{Na}^{+}$induced a prompt $\mathrm{pH}_{\mathrm{i}}$ recovery, and 1 $\mathrm{mmol} / \mathrm{l}$ amiloride almost totally inhibited this process. The average rate of $\mathrm{Na}^{+}$-dependent $\mathrm{pH}_{\mathrm{i}}$ recovery was $1.42 \pm 0.07 \mathrm{pH}$ unit $/ \mathrm{min}(n=9)$ and $0.03 \pm 0.004 \mathrm{pH}$ unit/min $(n=7)$ in the absence and presence of amiloride, respectively. When $20 \mathrm{mmol} / 1 \mathrm{NH}_{4} \mathrm{Cl}$ pulse technique was used to acidify the cells instead of nigericin, the cells showed a very similar $\mathrm{Na}^{+}$-dependent $\mathrm{pH}_{\mathrm{i}}$ recovery $(1.38 \pm 0.12 \mathrm{pH}$ unit $/ \mathrm{min}, n=5)$, which was again completely inhibited by $1 \mathrm{mmol} / \mathrm{l}$ amiloride. These results indicate that HLE cells recover from acid load mainly through the operation of a $\mathrm{Na}^{+} / \mathrm{H}^{+}$ exchanger in the absence of $\mathrm{HCO}_{3}{ }^{-} / \mathrm{CO}_{2}$. They also suggest that the problem of proton leak by residual nigericin would be minimal, if any, in our system.
As shown in Figure $5 \mathrm{~b}, \mathrm{pH}_{\mathrm{i}}$ recovery from acid load in the presence of $\mathrm{HCO}_{3}{ }^{-} / \mathrm{CO}_{2}$ was also totally dependent on extracellular $\mathrm{Na}^{+}$. In this case, however, the $\mathrm{Na}^{+}-$ dependent $\mathrm{pH}_{\mathrm{i}}$ recovery was only partially inhibited by amiloride. Thus the average rate of $\mathrm{Na}^{+}$-dependent $\mathrm{pH}_{\mathrm{i}}$ recovery was $0.94 \pm 0.06 \mathrm{pH}$ unit $/ \mathrm{min}(n=12)$ and $0.11 \pm 0.01 \mathrm{pH}$ unit $/ \mathrm{min}(n=11)$ in the absence and presence of amiloride, respectively, indicating that in addition to the $\mathrm{Na}^{+} / \mathrm{H}^{+}$exchanger, another mechanism is operating in the presence of $\mathrm{HCO}_{3}^{-} / \mathrm{CO}_{2}$. To test for the involvement of a $\mathrm{Na}^{+}-\mathrm{HCO}_{3}{ }^{-}$cotransporter in this process, we applied DIDS, a well-known inhibitor of this cotransporter. As also shown in Figure $5 \mathrm{~b}$, the joint application of amiloride and DIDS $(0.3 \mathrm{mmol} / \mathrm{l})$ completely inhibited the $\mathrm{Na}^{+}$-dependent $\mathrm{pH}_{\mathrm{i}}$ recovery $(n=5)$. When DIDS was applied to HLE cells incubated in standard $\mathrm{HCO}_{3}{ }^{-}$solution, steadystate $\mathrm{pH}_{\mathrm{i}}$ decreased from $7.46 \pm 0.06$ to $7.33 \pm 0.05$ after 3 minutes $(P<0.01 ; n=6)$.

Although these results were consistent with the operation of a $\mathrm{Na}^{+}-\mathrm{HCO}_{3}{ }^{-}$cotransporter, a $\mathrm{Na}^{+}$-dependent $\mathrm{Cl}^{-} / \mathrm{HCO}_{3}{ }^{-}$exchanger could be involved also. To test for $\mathrm{Cl}^{-}$-dependency of the $\mathrm{pH}_{\mathrm{i}}$ recovery, cells were incubated in $\mathrm{Cl}^{-}$-free $\mathrm{HCO}_{3}{ }^{-}$solution for more than 30 minutes to deplete intracellular $\mathrm{Cl}^{-}$. These cells showed a very similar $\mathrm{Na}^{+}$-dependent $\mathrm{pH}_{\mathrm{i}}$ recovery in the presence of amiloride. Indeed, the rate of $\mathrm{pH}_{\mathrm{i}}$ recovery in the absence $\mathrm{Cl}^{-}(0.11 \pm 0.01 \mathrm{pH}$ unit $/ \mathrm{min} ; n=13)$ was not significantly different from that in standard $\mathrm{HCO}_{3}$ solution containing amiloride. Moreover, the $\mathrm{pH}_{\mathrm{i}}$ recovery was again completely inhibited by the joint application of amiloride and DIDS $(n=5)$, indicating that the DIDS-sensitive $\mathrm{pH}_{\mathrm{i}}$ recovery is independent of $\mathrm{Cl}^{-}$.

Since NBC-1 is known to be electrogenic (5-8), we next tested electrogenicity of the $\mathrm{pH}_{\mathrm{i}}$ recovery in $\mathrm{Cl}^{-}$free $\mathrm{HCO}_{3}{ }^{-}$solution. After acidification by nigericin, cells were exposed to $\mathrm{Na}^{+}$-free, $\mathrm{Cl}^{-}$-free $\mathrm{HCO}_{3}{ }^{-}$solution containing a $\mathrm{K}^{+}$-ionophore, valinomycin $(5 \mu \mathrm{mol} / \mathrm{l})$. Subsequently, $72 \mathrm{mmol} / 1 \mathrm{Na}^{+}$-gluconate solution containing either low $(2 \mathrm{mmol} / \mathrm{l}$, solution $\mathrm{h})$ or high $(77$ $\mathrm{mmol} / \mathrm{l}$, solution $\mathrm{g}$ ) $\mathrm{K}^{+}$was applied in the presence of both valinomycin and amiloride. Since NBC-1 is considered to carry a net negative charge by transporting more $\mathrm{HCO}_{3}{ }^{-}$than $\mathrm{Na}^{+}$, the less-negative membrane potentials, induced by valinomycin and a high- $\mathrm{K}^{+}$solution, should be more favorable for $\mathrm{HCO}_{3}{ }^{-}$influx as

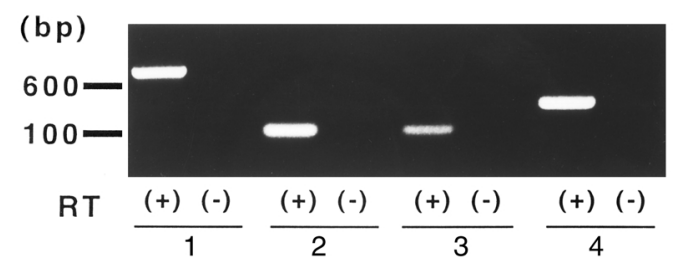

Figure 4

The expression of NBC-1 mRNAs in HLE cells. RT-PCR analysis with $(+)$ or without $(-)$ the reverse transcription step (RT). Lanes 1 and 4: the common regions in NBC-1. Lane 2: the PNBC-1-specific region. Lane 3: the kNBC-1-specific region. 

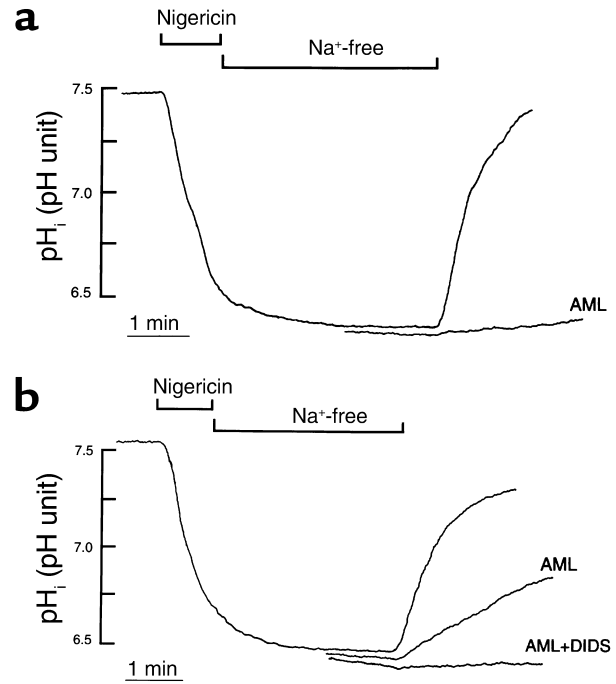

\begin{abstract}
Figure 5
(a) $\mathrm{pH}_{\mathrm{i}}$ recovery from acid in $\mathrm{HLE}$ cells. Results from two different experiments in the absence of $\mathrm{HCO}_{3}-\mathrm{CO}_{2}$. Cells were acidified by nigericin in solution a (Table 1 ); then the perfusate was changed to solution b. $\mathrm{pH}_{\mathrm{i}}$ recovery was induced by solution a with or without 1 $\mathrm{mmol} / \mathrm{I}$ amiloride (AML). (b) Three different experiments in the presence of $\mathrm{HCO}_{3}-\mathrm{CO}_{2}$. Cells were acidified in solution $\mathrm{c}$; then the perfusate was changed to solution $\mathrm{d}$. Thereafter, $\mathrm{pH}_{\mathrm{i}}$ recovery was induced by solution $\mathrm{c}$, solution $\mathrm{c}$ with $1 \mathrm{mmol} / \mathrm{l} \mathrm{AML}$, or solution $\mathrm{c}$ with $1 \mathrm{mmol} / \mathrm{I} \mathrm{AML}$ and $0.3 \mathrm{mmol} / \mathrm{I}$ DIDS.
\end{abstract}

shown previously in renal proximal tubular cells (17). As expected, the rate of $\mathrm{pH}_{\mathrm{i}}$ recovery was indeed faster in the high- $\mathrm{K}^{+}$solution $(0.09 \pm 0.01 \mathrm{pH}$ unit $/ \mathrm{min} ; n=8)$ than that in the low- $\mathrm{K}^{+}$solution $(0.04 \pm 0.01 \mathrm{pH}$ unit/min; $n=8 ; P<0.01$ ), supporting the electrogenicity of this process. When $0.8 \mathrm{mmol} / \mathrm{l}$ quinine- $\mathrm{HCl}$ was used instead of valinomycin to inhibit the $\mathrm{K}^{+}$conductance, the cells showed comparable $\mathrm{pH}_{\mathrm{i}}$ recovery in low$\mathrm{K}^{+}(0.08 \pm 0.01 \mathrm{pH}$ unit $/ \mathrm{min} ; n=6)$ and high- $\mathrm{K}^{+}$solution $(0.08 \pm 0.01 \mathrm{pH}$ unit $/ \mathrm{min} ; n=6, \mathrm{NS})$, ruling out the involvement of $\mathrm{K}^{+}-\mathrm{HCO}_{3}{ }^{-}$cotransporter.

The results thus far strongly suggest that HLE cells have a $\mathrm{Cl}^{-}$-independent, electrogenic $\mathrm{Na}^{+}-\mathrm{HCO}_{3}-$ cotransport activity compatible with NBC-1. To further validate this view, we examined the effects of a specific hammerhead ribozyme against NBC-1 (RZ-NBC), which was designed to target at the common region of human NBC-1 mRNA. Consistent with the highly efficient ability of hammerhead ribozyme to inhibit gene expression (20), adenovirus-mediated transfer of RZ-NBC into HLE cells quite effectively suppressed the expression of NBC-1 protein as estimated by Western blot analysis (Figure 6). In cells transfected with RZ-NBC, the $\mathrm{pH}_{\mathrm{i}}$ recovery from acid load in $\mathrm{Cl}^{-}$-free $\mathrm{HCO}_{3}{ }^{-}$solution containing amiloride was markedly slowed (Figure 7a), and the residual DIDS-sensitive $\mathrm{Na}^{+}-\mathrm{HCO}_{3}{ }^{-}$cotransport activity at 48 hours was only $20 \pm 3 \%(n=12)$ of the control value (Figure 7b). These effects of RZ-NBC were specific to NBC-1, since the $\mathrm{Na}^{+} / \mathrm{H}^{+}$exchange activity assayed as amiloride-sensitive $\mathrm{pH}_{\mathrm{i}}$ recovery was unaffected by RZ-NBC (Figure 7c). To rule out any nonspecific effects that might be evoked by ribozyme transfer, we tested another hammerhead ribozyme (RZ-MTP) targeting against the microsomal triglycerides transfer protein that mediates apoB secretion from the liver (21). Unlike RZ-NBC, RZ-MTP had no effects on the expression of NBC-1 protein (Figure 6) or the $\mathrm{Na}^{+}-$ $\mathrm{HCO}_{3}{ }^{-}$cotransport activity (Figure $7 \mathrm{~b}$ ).

\section{Discussion}

To determine the localization of NBC- 1 in human and rat eyes, we used the anti-C-terminal $\mathrm{Ab}$ that recognizes both kNBC-1 and pNBC-1 or the anti-N-termi$\mathrm{nal} \mathrm{Ab}$ 's that can discriminate between these isoforms. These Ab's were raised against highly specific regions of human NBC-1 and are unlikely to recognize other $\mathrm{Na}^{+}$-dependent and $\mathrm{Na}^{+}$-independent $\mathrm{HCO}_{3}{ }^{-}$transport molecules cloned so far $(12,27)$. Our results indicate that NBC-1 is present in the corneal endothelium, trabecular meshwork, ciliary epithelium, and lens epithelium. This localization potentially could explain the occurrence of ocular abnormalities in association with NBC-1 inactivation.

We have identified recently that the human corneal endothelial cells have the $\mathrm{Na}^{+}-\mathrm{HCO}_{3}{ }^{-}$cotransport activity and express mRNAs of both $\mathrm{kNBC}-1$ and $\mathrm{pNBC}-1$ (13). The present study further supports the view that NBC- 1 represents the $\mathrm{Na}^{+}-\mathrm{HCO}_{3}{ }^{-}$cotransport activity in the corneal endothelium. Although we have detected the expression of both NBC-1 isoforms in the human and rat corneal endothelium, a recent study in the bovine corneal endothelium reported the expression of pNBC-1 only (14). We do not know the exact reason for the discrepant results, but species difference could be responsible. The corneal endothelium transports fluid, $\mathrm{Na}^{+}$, and $\mathrm{HCO}_{3}{ }^{-}$out of the corneal stroma into the aqueous humor, and this process is considered to be essential for the maintenance of corneal hydration and transparency (28). Therefore, the inactivation of NBC1 may have a significant impact on the corneal homeostasis. In particular, the reduction of $\mathrm{HCO}_{3}{ }^{-}$efflux will increase the $\mathrm{pH}$ in the stroma, which may act in favor of $\mathrm{Ca}^{2+}$ deposition. Usually, the opacity of band keratopathy is caused by $\mathrm{Ca}^{2+}$ deposition into Bowman's mem-

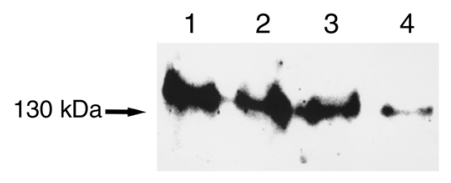

\section{Figure 6}

Effects of RZ-NBC on the expression of NBC-1 protein in HLE cells estimated by Western blot analysis. The Ab against NBC-1 C terminus was used, and a representative blot from three independent experiments is shown. Lane 1: nontransfected control cells. Lane 2: cells transfected with adenovirus vector carrying LacZ. Lane 3: cells transfected with adenovirus vector carrying RZ-MTP. Lane 4: cells transfected with adenovirus vector carrying RZ-NBC. 

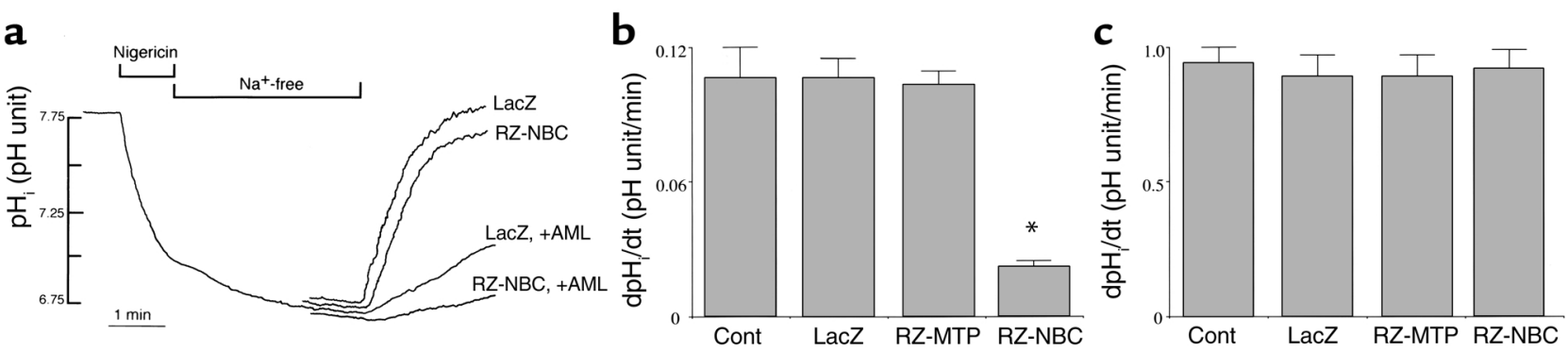

Figure 7

Effects of RZ-NBC on the transport activities in HLE cells. (a) $\mathrm{pH}_{\mathrm{i}}$ recovery from acid load in the absence of $\mathrm{Cl}^{-}$. Two different experiments from cells transfected with adenovirus vector carrying $\mathrm{LacZ}$ or adenovirus vector carrying RZ-NBC. (b) $\mathrm{Na}^{+}-\mathrm{HCO}_{3}{ }^{-}$cotransport activity determined as DIDS-sensitive $\mathrm{pH}_{\mathrm{i}}$ recovery in the $\mathrm{Cl}^{-}$-free $\mathrm{HCO}_{3}{ }^{-}$solution (solution e) containing $1 \mathrm{mmol} / \mathrm{l}$ amiloride. Cont, nontransfected control cells. Numbers of observations are 12 (Cont), 12 (LacZ), 10 (RZ-MTP), and 12 (RZ-NBC). ${ }^{*} P<0.001$ compared with Cont. (c) $\mathrm{Na}^{+} / \mathrm{H}^{+}$exchange activity determined as amiloride-sensitive $\mathrm{pH}_{i}$ recovery in solution e. Numbers of observations are 12 (Cont), 10 (LacZ), 9 (RZ-MTP), and $10(\mathrm{RZ}-\mathrm{NBC}) \cdot \mathrm{dpH} / \mathrm{dt}$, initial rate of $\mathrm{pH}_{\mathrm{i}}$ recovery.

brane. When associated with isolated pRTA, it is known to occur without any systemic $\mathrm{Ca}^{2+}$ abnormality (3).

The present study suggests that the $\mathrm{Na}^{+}-\mathrm{HCO}_{3}{ }^{-}$ cotransport activity detected previously in human trabecular meshwork cells (25) could be due to NBC-1. Since the trabecular meshwork is the main site for aqueous outflow in the human eye (29), it is tempting to speculate that the inactivation of NBC-1 may somehow alter the properties of trabecular meshwork cells so as to increase the resistance of aqueous outflow. In particular, trabecular meshwork cells are known to have contractile properties, which may be influenced by $\mathrm{Ca}^{2+}$ influx through voltage-dependent $\mathrm{L}$-type $\mathrm{Ca}^{2+}$ channels (30). The electrogenic nature of NBC-1 may, therefore, serve to stabilize the membrane potentials, which could be important for the regulation of $\mathrm{Ca}^{2+}$ influx and the contractility of these cells. However, the exact mechanism by which the trabecular meshwork alters its hydraulic resistance remains to be determined, and future studies will be required to clarify the role of NBC- 1 in this process. The detection of NBC- 1 in the ciliary body suggests that NBC-1 also may be involved in the production of aqueous humor. In fact, the presence of $\mathrm{Na}^{+}-\mathrm{HCO}_{3}{ }^{-}$cotransport activity in the ciliary epithelium has been suggested $(23,24)$. However, the contribution of other $\mathrm{HCO}_{3}{ }^{-}$transporters may be more important in the process of aqueous humor production $(23,31)$. On the other hand, we could not detect NBC-1 in the retina, where a $\mathrm{Na}^{+}-\mathrm{HCO}_{3}{ }^{-}$cotransport activity has been also reported (32). Probably, other transport molecules, such as NBC-2 (33), may be responsible for the cotransport activity in the retina.

Since previous studies failed to detect the $\mathrm{Na}^{+}-\mathrm{HCO}_{3}{ }^{-}$ cotransport activity in mammalian lens epithelia (26), the immunohistological detection of NBC-1 in the lens epithelium in both human and rat eyes was quite surprising. However, our analysis on HLE cells, which retain the characteristics of the human lens epithelium (18), supported a view that NBC-1 is really expressed in the lens epithelium. Thus, RT-PCR analysis detected mRNAs of both kNBC-1 and pNBC-1, and Western blot analysis confirmed the expression of $\mathrm{NBC}-1$ protein in these cells. In addition, functional analysis revealed the presence of $\mathrm{Cl}^{-}$-independent, electrogenic $\mathrm{Na}^{+}-\mathrm{HCO}_{3}{ }^{-}$ cotransport activity that was sensitive to DIDS. Furthermore, the specific ribozyme against NBC-1 markedly suppressed this activity as well as the expression of NBC- 1 protein. The physiological properties of NBC-1 thus characterized in HLE cells are very similar to those in the human corneal endothelial cells (13). In addition, since the application of DIDS decreased steady-state $\mathrm{pH}_{\mathrm{i}}, \mathrm{NBC}-1$ in the lens epithelium most likely functions as a bicarbonate uptake system into cells as also shown in the corneal endothelium (13). a

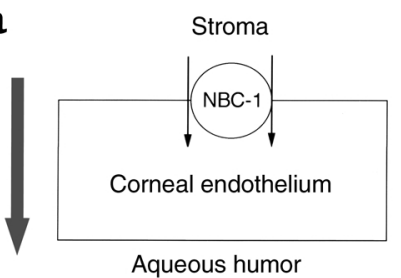

c

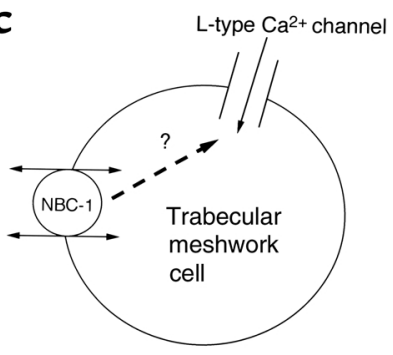

b

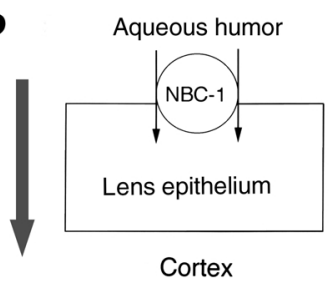

d

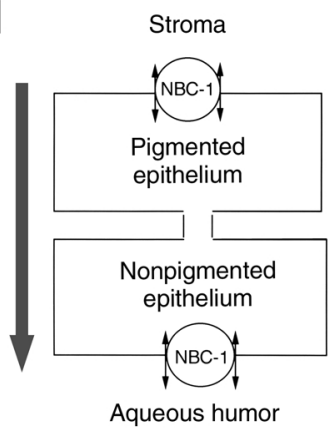

\section{Figure 8}

Possible roles of NBC- 1 in the ocular tissues. Large arrows indicate the direction of net fluid transport. In the cornea (a) and lens (b), NBC-1 likely contributes to the net fluid transport. In the trabecular meshwork cells (c), NBC-1 may affect the contractility of these cells via interaction with L-type $\mathrm{Ca}^{2+}$ channels. In the ciliary epithelium (d), the contribution of NBC-1 to the net fluid transport remains to be established. 
The lens is an avascular tissue, and simple diffusion of nutrients into the lens seems to be insufficient to account for its metabolic consumption (34). Instead, the lens epithelium is considered to play a central role in the maintenance of lens homeostasis and integrity $(35,36)$. A recent study indeed demonstrated that the cultured lens epithelial cell layers and rabbit lenses in vitro actively transport fluid from their anterior to their posterior sides against a hydrostatic pressure (37). Based on the observed transport rates and the known presence of the water channel aquaporin-1 in lens epithelium (38), the active fluid transport by the lens epithelium was considered of great importance for lens homeostasis (37). Our present results, together with the existence of anterior side-positive, translenticular potential difference depending on both $\mathrm{Na}^{+}$and $\mathrm{HCO}_{3}{ }^{-}$ ions (39), strongly suggest that NBC-1 plays a major role in the active fluid transport by the lens epithelium. The presence of membrane-associated carbonic anhydrase in the lens epithelium also supports the importance of $\mathrm{HCO}_{3}{ }^{-}$transport in the lens (40). On the other hand, the diffuse cytosolic staining in the lens epithelium suggests that $\mathrm{NBC}-1$ may also serve as a $\mathrm{pH}$ regulator of intracellular organelles. A recent study in the rat brain favors such multiple roles of NBC-1 (41). Transparency of the lens could be dependent on several physical properties, including the highly ordered protein structure and the homeostasis of intercellular and intracellular volume $(35,36)$. The inactivation of NBC-1 in the lens epithelium could somehow perturb these critical properties, which would ultimately result in cataract formation.

Figure 8 summarizes possible roles of NBC-1 in the ocular tissues. Previous studies have not detected major differences in the physiological properties of NBC-1 isoforms (5-8), and we observed very similar distribution patterns of $\mathrm{kNBC}-1$ and $\mathrm{pNBC}-1$ in the eye. It has been generally accepted that $\mathrm{kNBC}-1$ functions as a bicarbonate exit pathway from renal proximal tubular cells in vivo with the stoichiometry of $1 \mathrm{Na}^{+}$to $3 \mathrm{HCO}_{3}{ }^{-}$ (42). Recent studies, however, suggested that this transport stoichiometry, one of the major determinants of transport direction of NBC-1, may not be fixed but may vary depending on the conditions of cells (43-45). Moreover, rat $\mathrm{kNBC}-1$, when expressed in Xenopus oocytes, is reported to function with the $1 \mathrm{Na}^{+}$to 2 $\mathrm{HCO}_{3}{ }^{-}$stoichiometry $(46,47)$. Therefore, it would be not unreasonable to speculate that $\mathrm{kNBC}-1$ can also operate as a bicarbonate uptake system into cells in other tissues such as the corneal endothelium. Nevertheless, we cannot exclude the possibility that these NBC-1 isoforms may have slightly different functional roles. In this regard, it is interesting to note that a patient having a nonsense mutation in the $\mathrm{kNBC}$ 1 -specific region presented glaucoma but not band keratopathy or cataracts (48). Clearly, future studies will be required to understand the more precise roles of NBC- 1 in the ocular tissues, and such knowledge will not only help improve the efficiency of corneal trans- plantation but also have significant impact on the therapeutic strategies for glaucoma and cataracts.

\section{Acknowledgments}

This study was supported in part by grant 12671024 from the Ministry of Education, Science and Culture of Japan. Anti-NBC-1 Ab's were supplied by Kumamoto Immunochemical Laboratory Co. (Kumamoto, Japan).

1. Donckerwolcke, R.A., Van Stekelenburg, G.J., and Tiddens, H.A. 1970. A case of bicarbonate-losing renal tubular acidosis with defective carboanhydrase activity. Arch. Dis. Child. 45:769-773.

2. Winsnes, A., Monn, E., Stokke, O., and Feyling, T. 1979. Congenital persistent proximal type renal tubular acidosis in two brothers. Acta Paediatr. Scand. 68:861-868.

3. Braverman, D.E., and Snyder, W.E. 1987. A case report and review of band keratopathy. Metab. Pediatr. Syst. Ophthalmol. 70:39-41.

4. Igarashi, T., et al. 1999. Mutations in SLC4A4 cause permanent isolated proximal renal tubular acidosis with ocular abnormalities. Nat. Genet. 23:264-266.

5. Romero, M.F., Hediger, M.F., Boulpaep, E.L., and Boron, W.F. 1997. Expression cloning and characterization of a renal electrogenic $\mathrm{Na}^{+} / \mathrm{HCO}_{3}{ }^{-}$cotransporter. Nature. 387:409-413.

6. Burnham, C.E., Amlal, H., Wang, Z., Shull, G.E., and Soleimani, M. 1997. Cloning and functional expression of a human kidney $\mathrm{Na}^{+}: \mathrm{HCO}_{3}$ cotransporter. J. Biol. Chem. 272:19111-19114.

7. Abuladze, N., et al. 1998. Molecular cloning, chromosomal localization, tissue distribution, and functional expression of the human pancreatic sodium bicarbonate cotransporter. J. Biol. Chem. 273:17689-17695.

8. Choi, I., Romero, M.F., Khandoudi, N., Bril, A., and Boron, W.F. 1999. Cloning and characterization of a human electrogenic $\mathrm{Na}^{+}-\mathrm{HCO}_{3}$ cotransporter isoform (hhNBC). Am. J. Physiol. 276:C576-C584.

9. Abuladze, N., et al. 2000. Structural organization of the human NBC1 gene: $\mathrm{kNBC} 1$ is transcribed from an alternative promoter in intron 3. Gene. 251:109-122.

10. Alpern, R.J. 1990. Cell mechanisms of proximal tubule acidification. Physiol. Rev. 70:79-114.

11. Schmitt, B.M., Biemesderfer, D., Romero, M.F., Boulpaep, E.L., and Boron, W.F. 1999. Immunolocalization of the electrogenic $\mathrm{Na}^{+}-\mathrm{HCO}_{3}$ cotransporter in mammalian and amphibian kidney. Am. J. Physiol. 276:F27-F36.

12. Soleimani, M., and Burnham, C.E. 2000. Physiologic and molecular aspects of the $\mathrm{Na}^{+}: \mathrm{HCO}_{3}{ }^{-}$cotransporter in health and disease processes. Kidney Int. 57:371-384.

13. Usui, T., et al. 1999. Functional and molecular evidence for $\mathrm{Na}^{+}-\mathrm{HCO}_{3}$ cotransporter in human corneal endothelial cells. Pflügers Arch. 438:458-462.

14. Sun, X.C., Bonanno, J.A., Jelamski, S., and Xie, Q. 2000. Expression and localization of $\mathrm{Na}^{+}-\mathrm{HCO}_{3}{ }^{-}$cotransporter in bovine corneal endothelium. Am. J. Physiol. 279:C1648-C1655.

15. Quigley, H.A. 1996. Number of people with glaucoma worldwide. Br. J. Ophthalmol. 80:389-393.

16. Thylefors, B. 1998. Prevention of blindness-WHO's mission for vision. World Health Forum. 19:53-59.

17. Hara, C., et al. 2000. Intracellular $\mathrm{pH}$ regulatory mechanism in a human renal proximal cell line (HKC-8): evidence for $\mathrm{Na}^{+} / \mathrm{H}^{+}$exchanger, $\mathrm{Cl}^{-}$ $/ \mathrm{HCO}_{3}^{-}$exchanger, and $\mathrm{Na}^{+}-\mathrm{HCO}_{3}^{-}$cotransporter. Pflügers Arch. 440:713-720.

18. Ibaraki, N., et al. 1998. Human lens epithelial cell line. Exp. Eye Res. 67:577-585.

19. Thomas, J.A., Buchsbaum, R.N., Zimnick, A., and Racker, F. 1979. Intracellular $\mathrm{pH}$ measurements in Ehrlich ascites tumor cells utilizing spectroscopic probes generated in situ. Biochemistry. 18:2210-2218.

20. Wang, J.P., et al. 1999. Hammerhead ribozyme cleavage of apolipoprotein B mRNA generates a truncated protein. J. Biol. Chem. 274:24161-24170.

21. Chang, B.H.J., et al. 1999. Liver-specific inactivation of the abetalipoproteinemia gene completely abrogates very low density lipoprotein/low density lipoprotein in a viable conditional knockout mouse. J. Biol. Chem. 274:6051-6055.

22. Jentsch, T.J., Keller, S.K., Koch, M., and Wiederholt, M. 1984. Evidence for coupled transport of bicarbonate and sodium in cultured bovine corneal endothelial cells. J. Membr. Biol. 81:189-204.

23. Carre, D.A., Tang, C.S.R., Krupin, T., and Civan, M.M. 1992. Effect of bicarbonate on intracellular potential of rabbit ciliary epithelium. Curr. Eye Res. 11:609-624.

24. Wolosin, J.M., Bonanno, J.M., Hanzel, D., and Machen, T.E. 1991. Bicarbonate transport mechanism in rabbit ciliary body epithelium. Exp. Eye 
Res. 52:397-407.

25. Lepple-Wienhues, A., et al. 1994. Electrophysiological properties of cultured human trabecular meshwork cells. Exp. Eye Res. 59:305-311.

26. Jentsch, T.J., Von der Haar, B., Keller, S.K., and Wiederholt, M. 1985. Response of the intracellular potentials of cultured bovine lens cells to ions and inhibitors. Exp. Eye Res. 41:131-144.

27. Romero, M.F., and Boron, W.F. 1999. Electrogenic $\mathrm{Na}^{+} / \mathrm{HCO}_{3}{ }^{-}$cotransporters: cloning and physiology. Annu. Rev. Physiol. 61:699-723.

28. Hodson, S., and Miller, F. 1976. The bicarbonate ion pump in the endothelium which regulates the hydration of the rabbit cornea. J. Physiol. 263:563-577.

29. Bill, A. 1975. Blood circulation and fluid dynamics in the eye. Physiol. Rev. 55:383-417.

30. Steinhausen, K., Stumpff, F., Strauss, O., Thieme, H., and Wiederholt, M. 1999. Influence of muscarinic agonists and tyrosine kinase inhibitors on L-type $\mathrm{Ca}^{2+}$ channels in human and bovine trabecular meshwork cells. Exp. Eye Res. 70:285-293.

31. Helbig, H., Korbmacher, C., Kühner, D., Berweck, S., and Wiederholt, M. 1988. Characterization of $\mathrm{Cl}^{-} / \mathrm{HCO}_{3}{ }^{-}$exchange in cultured bovine pigmented ciliary epithelium. Exp. Eye Res. 47:515-523.

32. Hughes, B.A., Adorante, J.S., Miller, S.S., and Lin, H. 1989. Apical electrogenic $\mathrm{NaHCO}_{3}$ cotransport: a mechanism for $\mathrm{HCO}_{3}$ absorption across the retinal pigment epithelium. J. Gen. Physiol. 94:125-150.

33. Ishibashi, K., Sasaki, S., and Marumo, F. 1989. Molecular cloning of a new sodium bicarbonate cotransporter cDNA from human retina. Biochem. Biophys. Res. Commun. 246:535-538.

34. Harris, J.E., Hauschild, J.D., and Nordquist, L.T. 1955. Transport of glucose across the lens surface. Am. J. Ophthalmol. 39:161-169.

35. Mathias, R.T., and Rae, J.L. 1985. Transport properties of the lens. Am.J. Physiol. 249:C181-C190.

36. Mathias, R.T., Rae, J.L., and Baldo, G.J. 1997. Physiological properties of the normal lens. Physiol. Rev. 77:21-50.

37. Fischbarg, J., et al. 1999. Transport of fluid by lens epithelium. Am. J. Physiol. 276:C548-C557.
38. Stamer, W.D., Snyder, R.W., Smith, B.L., Agre, P., and Regan, J.W. 1994. Localization of aquaporin CHIP in the human eye: implications in the pathogenesis of glaucoma and other disorders of ocular fluid balance. Invest. Ophthalmol. Vis. Sci. 35:3867-3872.

39. Platsch, K.D., and Wiederholt, M. 1981. Effect of ion substitution and ouabain on short circuit current in the isolated human and rabbit lens. Exp. Eye Res. 32:615-625.

40. Ridderstråle, Y., Wistrand, P.J., and Brechue, W.F. 1994. Membrane-associated CA activity in the eye of the CA II-deficient mouse. Invest. Ophthalmol. Vis. Sci. 35:2577-2584.

41. Schmitt, B.M., et al. 2000. Na/ $\mathrm{HCO}_{3}$ cotransporters in rat brain: expression in glia, neurons, and choroid plexus. J. Neurosci. 20:6839-6848.

42. Yoshitomi, K., Burckhardt, B.C., and Frömter, E. 1985. Rheogenic sodium-bicarbonate cotransport in the peritubular cell membrane of rat renal proximal tubule. Pflügers Arch. 405:360-366.

43. Seki, G., Coppola, S., and Frömter, E. 1993. The $\mathrm{Na}^{+}-\mathrm{HCO}_{3}$ - cotransporter operates with a coupling ratio of $2 \mathrm{HCO}_{3}{ }^{-}$to $1 \mathrm{Na}^{+}$in isolated rabbit renal proximal tubule. Pflügers Arch. 425:409-416.

44. Seki, G., et al. 1996. On the mechanism of bicarbonate exit from renal proximal tubular cells. Kidney Int. 49:1671-1677.

45. Müller-Berger, S., Nesterov, V.V., and Frömter, E. 1997. Partial recovery of in vivo function by improved incubation conditions of isolated renal proximal tubule. II. Change of $\mathrm{Na}^{+}-\mathrm{HCO}_{3}{ }^{-}$cotransport stoichiometry and of response to acetazolamide. Pflügers Arch. 434:383-391.

46. Heyer, M., Müller-Berger, S., Romero, M.F., Boron, W.F., and Frömter, E. 1999. Stoichiometry of the rat kidney $\mathrm{Na}^{+}-\mathrm{HCO}_{3}^{-}$cotransporter expressed in Xenopus laevis oocytes. Pflügers Arch. 438:322-329.

47. Sciortino, C.M., and Romero, M.F. 1999. Cation and voltage dependence of rat kidney electrogenic $\mathrm{Na}^{+}-\mathrm{HCO}_{3}{ }^{-}$cotransporter, rkNBC, expressed in oocytes. Am. J. Physiol. 277:F611-F623.

48. Igarashi, T., et al. 2001. A novel nonsense mutation in the $\mathrm{Na}^{+} / \mathrm{HCO}_{3}^{-}$ cotransporter gene (SLC4A4) in a patient with permanent isolated proximal renal tubular acidosis and bilateral glaucoma. J. Am. Soc. Nephrol. 12:713-718. 